\title{
Narrativas visuais urbanas: uma análise das representações da Praça da Alfândega no Instagram
}

\author{
URBAN VISUAL NARRATIVES: \\ AN ANALYSIS OF THE REPRESENTATIONS OF PRAÇA DA ALFÂNDEGA ON INSTAGRAM
}

\section{Eduardo Campos Pellanda}

Doutor em Comunicação Social pela Pontifícia Universidade Católica do Rio Grande do Sul (PUC-RS) e professor membro do Programa de Pós-Graduação em Ciências da Comunicação da PUC-RS.

eduardo.pellanda@pucrs.br

\section{Gabrielli Tiburi Soares Pires}

Mestre em Comunicação Social pela Pontifícia Universidade Católica do Rio Grande do Sul (PUC-RS).

gabriellitiburi@gmail.com

\section{Luiza Carolina dos Santos}

Doutoranda em Comunicação e Informação na Universidade Federal do Rio Grande do Sul (UFRGS). Mestre em Comunicação Social pela Pontifícia Universidade Católica do Rio Grande do Sul (PUC-RS).

luizacdsantos@gmail.com

Recebido em 28 de fevereiro de 2016. Aceito em 29 de março de 2016.

\section{Resumo}

O presente artigo utiliza a metodologia da Analítica Cultural (MANOVICH, 2011) a fim de analisar a narrativa visual urbana da Praça da Alfândega, local turístico situado no centro de Porto Alegre, em dois períodos, durante e após a Feira do Livro, comparando-os e apontando indícios da formação de uma linguagem visual característica do local. Conclui-se que os registros feitos durante o evento evidenciam uma conexão social e um pertencimento à comunidade, transformando assim o lugar em espaço, onde a sociabilização reapropria os significados da geografia das interações.

Palavras-chave: Cultura da mobilidade. Analítica Cultural. Narrativa visual. 


\section{Abstract}

This article used the Cultural Analytics methodology (MANOVICH, 2011) to analyze the urban visual narrative of Praça da Alfândega, tourist site in the center of Porto Alegre, in two periods, during and after the Book Fair, comparing them and pointing indications of a visual language formation characteristic of that place. We conclude that the records made during the event reveal a social connection and a sense of belonging to the community, thereby transforming the place in space, where socialization reappropriates the meanings of the geography of interactions.

Keywords: Mobile culture. Cultural Analytics. Visual narrative.

\section{Introdução}

Os espaços coletivos de uma cidade alteram-se constantemente de acordo com a forma como são habitados e explorados pelo tecido humano. Com o passar do tempo e de pessoas, novas narrativas se constroem nesses espaços - narrativas essas que hoje são não apenas passíveis de registro com nossas câmeras, mas também de compartilhamento através de nossos dispositivos móveis. Enquanto andamos pela cidade, simbolizamos, registramos e compartilhamos criando narrativas comunicacionais urbanas. Essas narrativas podem dizer muito não apenas sobre os locais que ocupamos coletivamente, mas também sobre nossos modos de convívio e representação em sociedade.

Este artigo se propõe a analisar a narrativa visual urbana produzida pelos sujeitos que frequentaram a Feira do Livro de Porto Alegre através de um estudo comparativo das imagens geolocalizadas na Praça da Alfândega e arredores e compartilhadas no Instagram durante e após o evento.

Para tanto, partimos dos conceitos de territórios informacionais (LEMOS, 2007), nomadismo (MAFFESOLI, 2004), microconteúdo (IGARZA, 2009) e inflação estética (LIPOVETSKY; SERROY, 2015), na tentativa de compreender o contexto comunicacional e estético do mundo contemporâneo. Posteriormente traçamos um perfil histórico e social do objeto em questão, a Feira do Livro de Porto Alegre e o local no qual ela tradicionalmente ocorre, a central Praça da Alfândega, calcando-nos em Flôres (2005) para uma análise da praça enquanto local social, caracterizada não apenas por sua constituição arquitetônica, mas pelos eventos que nela ocorrem.

A coleta dos dados foi realizada através do IFTTT, sistema que possibilita salvar de forma simplificada imagens publicadas no Instagram de forma pública a partir de um local e hashtag determinados. Durante as duas semanas de coleta de dados, uma durante 
e outra após a Feira do Livro de Porto Alegre, obtivemos um total de 384 imagens, 276 no primeiro momento e 108 no segundo.

Como método de análise utilizamos a analítica cultural (MANOVICH, 2010; MANOVICH; DOUGLASS; ZEPEL, 2011), uma abordagem que possibilita também uma visão quantitativa no âmbito das ciências sociais, auxiliando na análise de um conjunto com número expressivo de imagens. Composta por duas etapas básicas, o processamento e a visualização das imagens, essa metodologia visa à exploração de padrões culturais em imagens compartilhadas através de redes sociais, buscando diferenças e constâncias. Realizamos a primeira etapa do processamento das imagens de forma manual, sistematizando os dados em categorias temáticas e, posteriormente, realizamos a visualização das imagens, utilizando também parâmetros como cor, brilho e saturação. Por fim, geramos a partir do ImageJ gráficos reduzidos e não-reduzidos e de visualização de mídia, técnica que possibilita a visão em conjunto e facilita a busca por padrões e discrepâncias.

O resultado do cruzamento da análise dos dados, a partir das visualizações e da utilização de gráficos e montagens com o arsenal teórico inicialmente apresentado pelos autores deste trabalho, pode ser observado na seção 5 deste artigo, apontando uma clara diferença na forma como se constitui a narrativa visual urbana no Instagram no período da Feira do Livro em comparação com o período posterior.

\section{Mobilidade informacional e a cultura visual urbana}

Andar pelas cidades, fotografar e compartilhar uma parte do cotidiano daquele local tornou-se uma atividade corriqueira, proporcionada pela ubiquidade das conexões e dos dispositivos móveis que nos acompanham. Ao alcance das mãos, sempre próximos e always on, smartphones, tablets e outras tecnologias informáticas móveis auxiliam em nossa comunicação, em nosso consumo de informações e em nossa produção de conteúdo. A profusão de imagens publicadas todos os dias nas plataformas de redes sociais ajudam a contar uma narrativa urbana e a formar uma linguagem visual desses ambientes, uma estética imbricada entre o ambiente físico e os elementos ali presentes, e as características culturais e comportamentais das plataformas de redes sociais.

Essa cultura em torno da mobilidade não é nova, mas é potencializada pelo desenvolvimento das tecnologias e pela restruturação das cidades, quando o contato com o ciberespaço deixa de ser restrito a um ponto fixo de conexão e passa a espalhar-se por quase todos os pontos da cidade através de conexões sem fio (como Wi-Fi, 3G, 4G, Bluetooth, RFID). Essa conexão proporciona zonas híbridas no território urbano, às quais Lemos (2007) dá o nome "territórios informacionais". "O território informacional não é o 
ciberespaço, mas o espaço movente, híbrido, formado pela relação entre o espaço eletrônico e o espaço físico" (LEMOS, 2007, p. 128). Ou "espaços de fusão", como denomina Micthell (2005): espaços em que as funções cotidianas saem de seus locais tradicionais e passam a ocupar espaços públicos e espaços de convívio, como parques, cafés, aeroportos.

Esses espaços híbridos proporcionados através da conexão constante potencializam um novo tipo de nomadismo, de uma relação efêmera e errante com o mundo e com os outros, calcada no encurtamento dos espaços através da mobilidade informacional (MAFFESOLI, 2004). Qualquer simples deslocamento diário, como ir ao trabalho, ou pequenas migrações, como viagens,

Tudo isso é tremendamente trivial, mas esconde uma importante dose de aventura, que pode ser desejada, assumida ou suportada, embora o problema não resida aí. Pode entender-se, então, como a forma contemporânea desse desejo de "outro lugar" se apodera regularmente das massas e dos indivíduos (MAFFESOLI, 2004, p. 29, tradução nossa). ${ }^{1}$

Essa vida errante e fluida proporcionada pelo nomadismo atual relaciona-se de modo novo com o tempo e o espaço. $\mathrm{O}$ dia passa a não ser mais dividido entre o horário de trabalho e o horário de descanso. O ócio e o trabalho dividem o mesmo espaço, sendo que o primeiro insere-se em fragmentos, ocupando-se de momentos de espera, de trânsito, ou momentos vazios, o que Igarza (2009) chama de "bolhas de ócio". Interstícios, esses, que passam a ser mais numerosos, porém curtos e fragmentados, caracterizando-se em

uma oferta heterogênea de brevidades, conteúdos de curtíssima duração, cápsulas que se consomem sem custo de deslocamento, que geralmente são de caráter publicitário (em troca, o usuário consome publicidade) e que não retém o usuário em um ambiente fechado, preso a um roteiro não participativo, sem oportunidades de bifurcação nem de personalização (IGARZA, 2009, p. 43 , tradução nossa). ${ }^{2}$

Esses períodos de ócio se manifestam em diversos momentos na vida cotidiana quando estamos em pausa, esperando por algo ou a caminho de algum lugar, espaços

1 Tradução para "Todo esto es tremendamente trivial, pero esconde una importante dosis de aventura, que puede ser deseada, asumida o soportada, aunque el problema no radique ahí. Puede comprenderse, entonces, como la modalidad contemporánea de ese deseo del "otro lugar" que se apodera regularmente de las masas y de los individuos".

2 Tradução para "una oferta heterogénea de brevedades, contenidos de cortísima duración, cápsulas que se consumen sin costo de desplazamiento, que generalmente son de contraprestación publicitaria (a cambio, el usuario consome publicidade) y que no retienen al usuario em um ámbito cerrado preso de um guión no-participativo sin oportunidades de bifurcación ni de personalización". 
de tempo que se inserem no nosso corrido dia a dia, como a espera de um atendimento médico ou o tempo de deslocamento de um transporte público (IGARZA, 2009). Como o ritmo de trabalho é muito acelerado, a pausa pode ser algo traumático. Ter que esperar em um mundo veloz é problemático e angustiante. Por isso, preencher esses momentos com conteúdos breves, microconteúdos, como denomina Igarza (2009), é uma forma de manter o ritmo e fugir da angústia da espera. Do mesmo modo, há outros períodos em que a pausa e a busca pelo ócio não decorrem de momentos em que somos forçados a esperar. O autor (2009) nos fala também em pausas no trabalho para realizar qualquer outra ação diversa, como consumir conteúdo audiovisual curto, ler notícias, pagar contas, acessar as redes sociais, ou jogar.

Microconteúdos são pensados para serem consumidos em pequenos fragmentos de tempo e se ajustam ao trajeto, podendo ser mesclados com outros conteúdos, com conversas interpessoais, sem prejuízo de se abandonar e retornar a eles (IGARZA, 2009). Ao explicar os microconteúdos on-line, Igarza (2009) defende que esse formato, embora breve, não perde o poder narrativo e de entretenimento, visto que a literatura, por exemplo, sempre teve formas curtas de contar histórias, "demonstrando que a capacidade de contar, entreter, relatar e, definitivamente, provocar um prazeroso desempenho imaginativo ao leitor não está vinculada ao tamanho da obra" (IGARZA, 2009, p. 161, tradução nossa). ${ }^{3}$ Esses microconteúdos podem ser e-mails, notícias, vídeos, jogos e também imagens.

O objetivo deste artigo é analisar a produção de uma linguagem visual construída em torno de um espaço público por meio de fotografias compartilhadas em redes sociais digitais. Essas imagens apresentam-se também como microconteúdos que preenchem essas bolhas de ócio tanto no momento da produção quanto no momento do consumo por outros e da interação social nas redes. Dessa produção de microconteúdos acabamos por colecionar fragmentos cotidianos, indicando essa errância diária como uma nova relação estética com as cidades.

Para Lipovetsky e Serroy (2015), vivemos em uma quarta era ${ }^{4}$ de estetização do mundo, em que os indivíduos são estéticos, ou transestéticos, e vivem, consomem e produzem em um regime de "inflação estética". Esse "[...] processo de estetização hipermoderno extrapola em muito as esferas de produção, tendo alcançado o consumo, as aspirações, os modos de vida, a relação com o corpo, o olhar para o mundo" (LIPOVETSKY; SERROY, 2015, p. 30). Pensando na produção de imagens cotidianas, a esfera de estetização colabora com e, ao mesmo tempo, é influenciada pela formação de uma identidade

3 Tradução para "demonstrando que la capacidad de contar, entreter, relatar, em definitiva, de provocar um gozoso rendimiento imaginativo em el lector, no está supeditada a la longitud de la obra".

4 A era "transestética", de uma hiperarte global, sucede a era da "artealização ritual", uma arte feita para os deuses; a "estetização aristocrática", voltada à nobreza; a estetização moderna, liberta da religião e da nobreza, voltada à arte pela arte (LIPOVETSKY; SERROY, 2015).

\footnotetext{
$44 \frac{\text { Comunicação \& Inovação, PPGCOM/USCS }}{\text { v. 17, n. 34 (40-58) maio-ago. } 2016}$
} 
fluida dos sujeitos, constantemente atualizada, pautada pelos gostos e pelos instantes vividos, não pelas reflexões profundas (LIPOVETSKY; SERROY, 2015).

O que gostamos de pôr em relevo não é mais tanto a nossa posição social e as nossas convicções estáveis e duráveis, mas nossa identidade móvel e flexível, as impressões sentidas num dado momento e que podem se transformar de uma situação a outra, ou seja, um eu desinstitucionalizado e fluido, descentrado e pontual (LIPOVETSKY; SERROY, 2015, p. 375). A relação de representação do eu, da vida cotidiana e também dos espaços urbanos é assim refletida na produção de instantâneos digitais fotográficos, como veremos a seguir, a partir da análise de publicações feitas na Praça da Alfândega em Porto Alegre.

\section{A Feira do Livro de Porto Alegre}

A Feira do Livro de Porto Alegre é, na atualidade, um dos eventos culturais de maior prestígio e público da cidade, considerada a maior feira do livro a céu aberto do continente americano. Sua primeira edição, já na Praça da Alfândega, data de 1955, período no qual a cidade contava com apenas 400 mil habitantes. Inspirada em uma feira realizada na cidade de Cinelândia, no Rio de Janeiro, e idealizada pelo jornalista Say Marques, hoje a Feira do Livro é organizada pela Câmara Rio-Grandense do Livro (CRL) e ocorre ininterruptamente há 61 anos. ${ }^{5}$

Naquela primeira edição em 1955, entretanto, o evento não possuía as dimensões contemporâneas, mas já trazia a ideia de aproximar a leitura e o livro da população, ocupando o espaço central da praça para tanto. A partir da década de 1990 ocorre uma ampliação das atividades realizadas na Feira do Livro, impulsionada pelo auxílio das leis de incentivo, que datam do mesmo período. A edição de 1995 passa a contemplar também uma programação específica para o público mais jovem - dez anos depois, em 2005, ocorre a criação de uma área voltada especificamente para crianças e adolescentes na feira.

Desde 2005 o evento é considerado patrimônio histórico e cultural do Rio Grande do Sul e em 2010 passa a ser reconhecido como o primeiro patrimônio imaterial da cidade de Porto Alegre. Em 2015, a 61 ${ }^{\text {a }}$ Feira do Livro de Porto Alegre teve duração de 17 dias, com uma agitada programação cultural que se estendeu de 30 de outubro a 15 de novembro.

A Praça da Alfândega, espaço onde tradicionalmente ocorre a Feira do Livro, localiza-se no Centro Histórico de Porto Alegre e sua origem data do final do século XVIII, ligada ao núcleo originário da cidade (FLÔRES, 2005). Sua função inicial de lugar de

5 Informações disponíveis no site da Feira do Livro de Porto Alegre: <http://www.feiradolivro-poa.com.br>. 
comércio passa por uma lenta transformação ao longo do século XIX, para, por fim, constituir-se como um espaço de lazer e sociabilidade da burguesia porto-alegrense:

Na década de trinta, a Praça da Alfandega foi considerada o centro da vida social de Porto Alegre. A leitura realizada em seu espaço revelava um grande pórtico de entrada da cidade que culminava em uma praça, que foi o ponto de encontro da sociedade, dos intelectuais, dos artistas e políticos, proporcionando uma visão de modernidade que vinculava o usuário ao lugar (FLÔRES, 2005, p. 81).

É importante compreender que uma praça, embora sempre criada a fim de cumprir uma determinada função, irá constituir-se, de fato, a partir dos eventos que nela tomam lugar, sem que suas características físicas e arquitetônicas possam delimitar sua função. Assim, a qualificação de uma praça e sua própria função podem alterar-se no decorrer do tempo - tal transformação é evidente, por exemplo, na Praça da Alfândega, que passa de um local historicamente associado ao comércio, posteriormente exercendo a função de aglutinar e conceder prestígio social e cultural, para, por fim, transformar-se em um local de passagem, de cotidiano.

Ainda que a função principal de uma praça possa alterar-se no tempo - e, com isso, a própria percepção social que se faz desse espaço -, também é preciso notar que "a praça é o lugar do convívio por excelência, local de encontro, de contato entre as pessoas. Nela encontram-se o privado e o público, configurando-se como cenário de momentos importantes da cidade e das ações da vida pública" (FLÔRES, 2005, p. 132). Marca-se, assim, a função social inerente ao espaço público da praça, característica essa que será essencial no decorrer da análise que este trabalho se propõe a realizar.

Ao redor da Praça da Alfândega encontramos edificações de importância histórica, cultural e arquitetônica, como o Memorial do Rio Grande do Sul e o prédio da antiga Previdência do Sul. Atualmente, alguns desses edifícios recebem outras atividades culturais já consagradas, como o Santander Cultural e o Museu de Arte do Rio Grande do Sul (MARGS), que cedem bianualmente seus espaços para a Bienal de Artes do Mercosul. Em 2015, a 10 a edição do evento ocorreu entre os dias 8 de outubro e 22 de novembro, dividindo, durante parte desse período, o entorno da Praça da Alfândega com a Feira do Livro - esse cruzamento entre os dois eventos pode ser claramente constatado nos dados coletados para este artigo, que serão discutidos adiante.

Além da exposição e venda de livros, a Feira do Livro de Porto Alegre comporta uma programação cultural ampla para diversas faixas etárias, com atividades como contação de histórias, leituras dramáticas, sessões de autógrafos, conversas com escritores, ilustradores e 
jornalistas, leituras mediadas, peças teatrais, seminários e ciclos de debates temáticos, concertos musicais, entre tantas outras. Na edição de 2015, para além da literatura, também se discutiu temas como arquitetura e urbanismo, acessibilidade, autismo e políticas de inclusão.

Para dimensionar em números o tamanho do evento, de acordo com a CDL, nessa última edição estiveram presentes 113 expositores, e ocorreram no total 48 programações artísticas, 24 oficinas, 220 encontros com escritores e aproximadamente 700 sessões de autógrafo. Na programação infantil ocorreram mais de 300 atividades e 145 encontros com autores em escolas, tanto no período que antecede à Feira quanto de forma paralela à programação da Praça da Alfândega.

Uma vez dimensionado o porte cultural da Feira do Livro de Porto Alegre, é importante ressaltar, para os fins deste artigo, que o ano de 2015 foi economicamente desfavorável para o Brasil, com corte de verbas em diversos setores - para a cultura, não foi diferente. Eventos literários já consagrados, como a Jornada Nacional de Literatura de Passo Fundo, foram cancelados devido à insuficiência de verbas, enquanto a Flip, Festa Literária Internacional de Paraty, manteve o evento operando com o menor orçamento da década. A Feira do Livro de Porto Alegre ocorreu com um corte de um terço de verba em comparação ao ano anterior, com um orçamento de aproximadamente $\mathrm{R} \$ 2$ milhões, obrigando a organização do evento a cancelar atrações de alto custo, como os músicos Emicida e Arnaldo Antunes, e a realizar cortes no valor das estruturas e na quantidade de funcionários (LUCCHESE, 2015).

Mesmo em um cenário econômico balançado, a $61^{\mathrm{a}}$ Feira do Livro de Porto Alegre comercializou cerca de R $\$ 445$ mil, apresentando um aumento de $11,25 \%$ nas vendas em comparação ao ano anterior. Passaram pelo evento, durante seus 17 dias de duração, aproximadamente 1,5 milhão de pessoas, representando um aumento de 7\% no público em relação à última edição $(\mathrm{G} 1,2015)$.

É possível evidenciar, portanto, que tanto a Feira do Livro de Porto Alegre quanto o próprio local em que ela ocorre, a Praça da Alfândega, estão relacionados ao imaginário, à história e à cultura da cidade, movimentando não apenas a economia ou possibilitando um espaço de diálogo para a literatura, mas também se constituindo parte importante da vida social dos sujeitos que por lá circulam e que representam esses espaços de formas distintas, seja anualmente, no caso da Feira, ou cotidianamente, no caso da Praça.

\section{Procedimentos metodológicos}

Para explorar padrões culturais presentes no conjunto de imagens publicadas no entorno da Praça da Alfândega em dois períodos, a fim de entender constâncias e diferenças 
ocasionadas por características visuais, utilizamos no presente artigo a metodologia da analítica cultural. Essa perspectiva teórico-metodológica foi desenvolvida como uma forma de análise da crescente oferta de conteúdos criados e compartilhados pelas pessoas na internet. Como exemplo, considerando somente a plataforma Instagram, são publicados mais de 60 milhões de vídeos e fotos por dia (INSTAGRAM, 2015). Assim, a utilização de abordagens quantitativas nas ciências sociais torna-se mais presente pelo volume de dados que o cotidiano apresenta. O que pensamos, o que vemos no nosso dia a dia e onde estamos é constantemente registrado na rede por nós mesmos, gerando essa quantidade enorme de dados que é muito significativa para o entendimento comunicacional atual.

O método consiste em uma "análise de fluxos e conjuntos de dados culturais massivos usando técnicas computacionais e de visualização" (MANOVICH, 2015), p. 1, tradução nossa $)^{6}$ e possui duas etapas-chave, o processamento e a visualização das imagens.

As imagens analisadas nesta pesquisa foram coletadas através do $\mathrm{IFTTT}^{7}$, um sistema que possibilita, por meio de uma programação simplificada e realizada através de ações pré-programadas, salvar, em uma planilha do Google Drive, fotografias publicadas em conta pública no Instagram com uma determinada hashtag ou em um determinado local. Para atingir o objetivo deste artigo, determinamos que a coleta fosse feita considerando o perímetro aproximado da Praça da Alfândega, localizada no Centro Histórico de Porto Alegre, no período de 9 a 15 de novembro e de 9 a15 de dezembro de 2015, sendo a primeira referente à última semana em que ocorreu a Feira do Livro de Porto Alegre, e a segunda, um mês após. O IFTTT não salva todas as imagens publicadas, o sistema faz uma varredura a cada hora e captura as 10 últimas publicações.

Foram coletadas 384 imagens no total, 276 no primeiro e 108 no segundo período. A primeira etapa de processamento das imagens foi realizada manualmente pelos autores, validando e sistematizando os dados e, posteriormente, dividindo as imagens em categorias temáticas. Essa categorização, juntamente a outros parâmetros das imagens, como cores, brilho e saturação, foi utilizada para realizar as visualizações, segunda etapa do processo.

Embora a vantagem do método seja explorar relações entre centenas ou milhões de imagens de forma computadorizada, a análise automatizada sempre possui limitações e por isso deve ser auxiliada pelo olhar humano (MANOVICH, DOUGLASS, ZEPEL, 2011). Posteriormente, o conjunto de imagens foi submetido ao ImageJ, um programa gratuito, escrito em Java, de código aberto e desenvolvido pelo Instituto

6 Tradução para "the analysis of massive cultural data sets and flows using computational and visualization techniques".

7 Sigla para "If This, Than That", expressão condicional vinda da linguagem de programação, equivalente em português a "Se isto, então aquilo". Disponível em: $<$ http://fttt.com>.

\footnotetext{
$48 \frac{\text { Comunicação \& Inovação, PPGCOM/USCS }}{\text { v. 17, n. 34 (40-58) maio-ago. } 2016}$
} 
Nacional de Saúde Mental estado-unidense. O processamento das imagens é feito de forma local, não on-line.

Por fim, a terceira etapa concentrou-se no desenvolvimento de gráficos reduzidos e não-reduzidos, ou de visualização de mídia (MANOVICH, 2010). Gerados a partir do ImageJ, os gráficos utilizam as próprias imagens para composição das visualizações e exploram as técnicas de montagem, de fatiamento e de sobreposição. Para entendermos o fluxo das publicações nos dois períodos, foram gerados também gráficos percentuais e numéricos. A primeira, a montagem, proporciona uma visualização geral das imagens em uma sequência de miniaturas formando um retângulo. Essa técnica permite uma visão das imagens em conjunto, o que facilita a visualização de padrões culturais. Além de uma visualização completa de todas as imagens, nesse formato foram analisadas as categorias temáticas. A técnica de fatiamento das imagens, ou visão ortogonal, compõe novas figuras com amostras de cada imagem preenchendo uma linha e uma coluna de pixels determinadas. A visualização em fatias gera uma imagem vertical, realizada por meio de uma fileira com a altura total da imagem e um pixel de largura, e outra horizontal, com a largura total da imagem e um pixel de altura. Ambas utilizando como base o pixel central. Com o programa ImageJ em execução, três janelas são mostradas, a da coleção das fotografias e a das duas visualizações em fatias. Assim, é possível movimentar o pixel tomado como base do fatiamento e também ver qual é a fotografia que está sendo representada em determinada fileira de pixels (horizontal ou vertical), a isso se deve a presença de duas linhas amarelas que aparecem nas figuras salvas dessas visualizações, como é possível notar nas Figuras 3 e 4. Por fim, a técnica de sobreposição, ou Z-project, realiza uma média dos pixels das imagens selecionadas, levando em consideração a mediana, o desvio padrão do brilho ou a intensidade mínima, máxima ou média, formando uma nova imagem.

Para a execução dessas visualizações no ImageJ, todas as imagens foram redimensionadas para o tamanho de $720 \times 720$ pixels e 72 DPI, pois o programa só realiza montagens com imagens do mesmo tamanho. Nesse caso, as que não possuíam essa proporção receberam a adição de bordas pretas para que não fosse realizado nenhum corte na imagem. A partir dessas visualizações, vistas a seguir, foi realizada a análise das imagens a fim de compreender como elas auxiliam na formação de uma linguagem visual desse ponto turístico da cidade.

\section{Análise das visualizações}

Como evidenciado anteriormente, o número de publicações coletadas no período referente à segunda semana da $61^{\mathrm{a}}$ Feira do Livro de Porto Alegre é maior ao do período 
correspondente a um mês após o evento. No mesmo período ocorria também a $10^{\mathrm{a}}$ Bienal do Mercosul nos prédios do Margs, do Memorial do Rio Grande do Sul e do Santander Cultural. As exposições da Bienal encerraram-se no dia 7 de dezembro, portanto, as imagens publicadas referentes a esse evento também são retroativas. No primeiro período foram coletadas 276 imagens, publicadas por 215 usuários únicos, uma média de 1,28 fotos por perfil, média que se manteve no segundo período $(1,2)$, apesar do menor número de publicações (108) e, consequentemente, de perfis únicos (90). Consideramos, para a realização desta pesquisa, esse espaço como um território informacional (LEMOS, 2007), marcado pela fusão entre o tecido urbano e suas representações no ciberespaço por meio das tecnologias móveis.

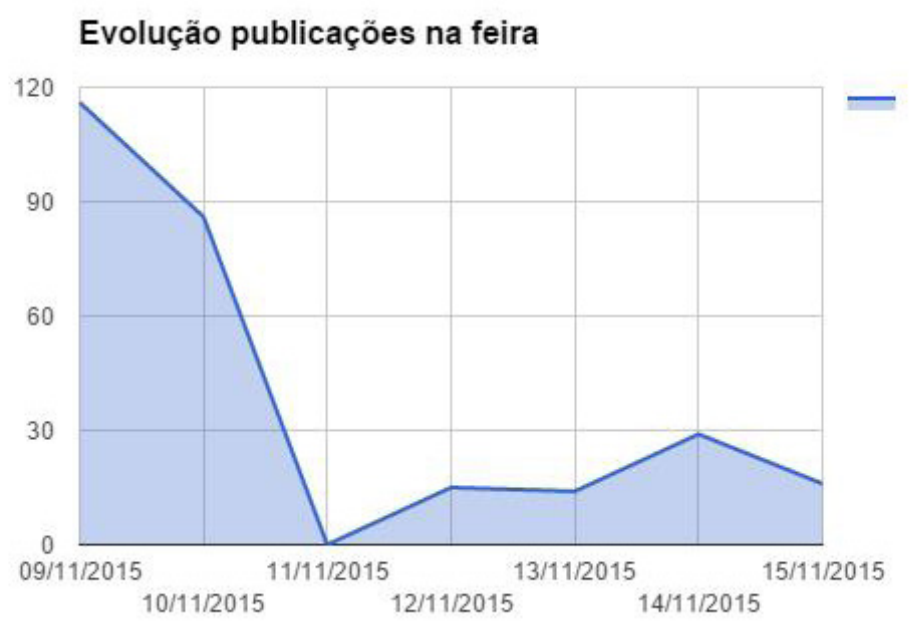

Figura 1 - Número de publicações por dia durante a Feira do Livro Fonte: Os autores (2016)

O maior número de publicações na Feira (Figura 1) corresponde aos dias 9 e 10, segunda e terça-feira (116 e 86 publicações, respectivamente), embora o movimento da Feira seja maior aos finais de semana, muitas das publicações são retroativas. Esses números devem-se, por exemplo, à presença do autor Eduardo Spohr, que participou da programação da Praça de Autógrafos no domingo, dia 8 de novembro. Já na Figura 2, o número de publicações por dia é mais constante, variando entre 11 e 21 publicações ao dia. 


\section{Evolução publicaçōes pós-feira}

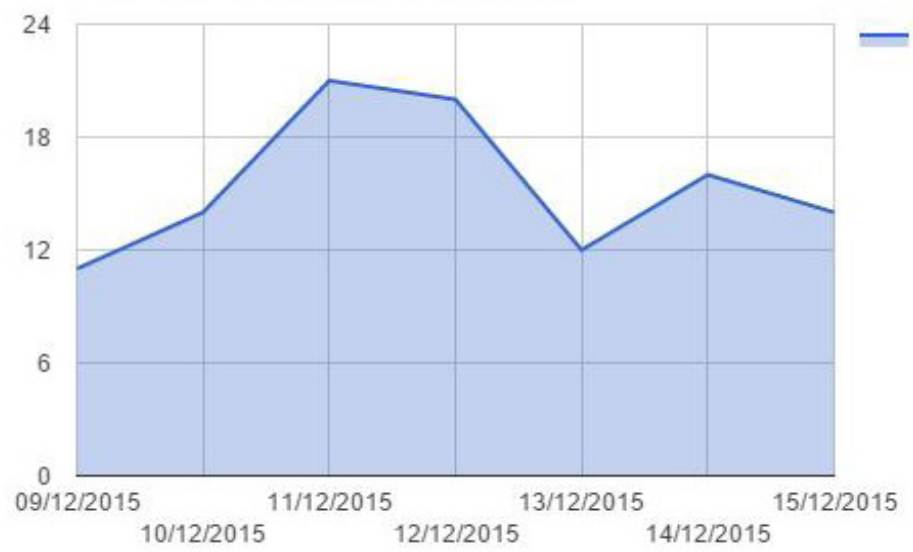

Figura 2 - Número de publicações por dia após a Feira do Livro

Fonte: Os autores (2016)

Observando todas as imagens em conjunto, por meio da técnica de montagem, é possível perceber diferenças visuais nas publicações dos dois períodos, conforme as Figuras 3 e 4.

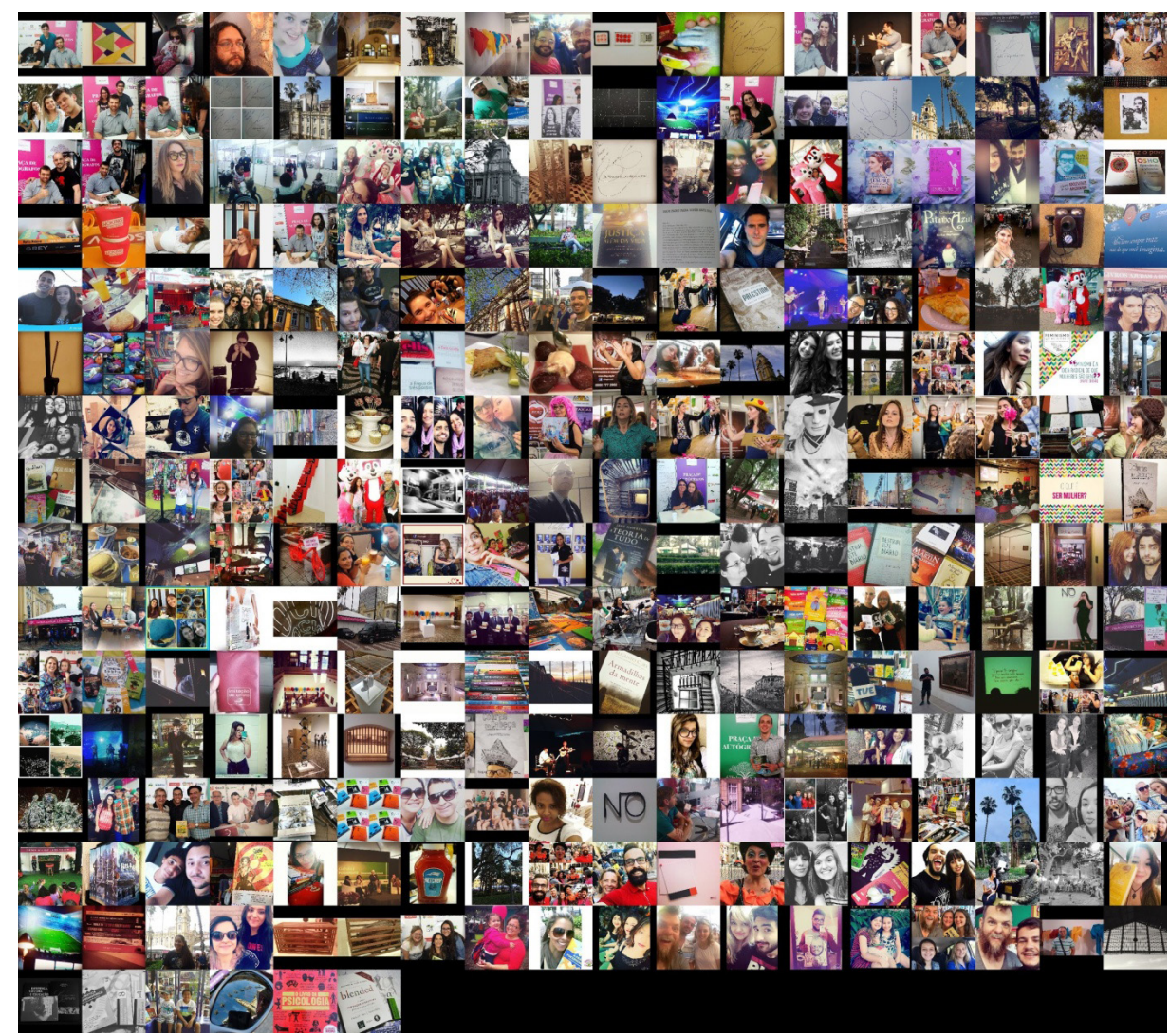

Figura 3 - Montagem das imagens durante a Feira do Livro

Fonte: Os autores (2016) 


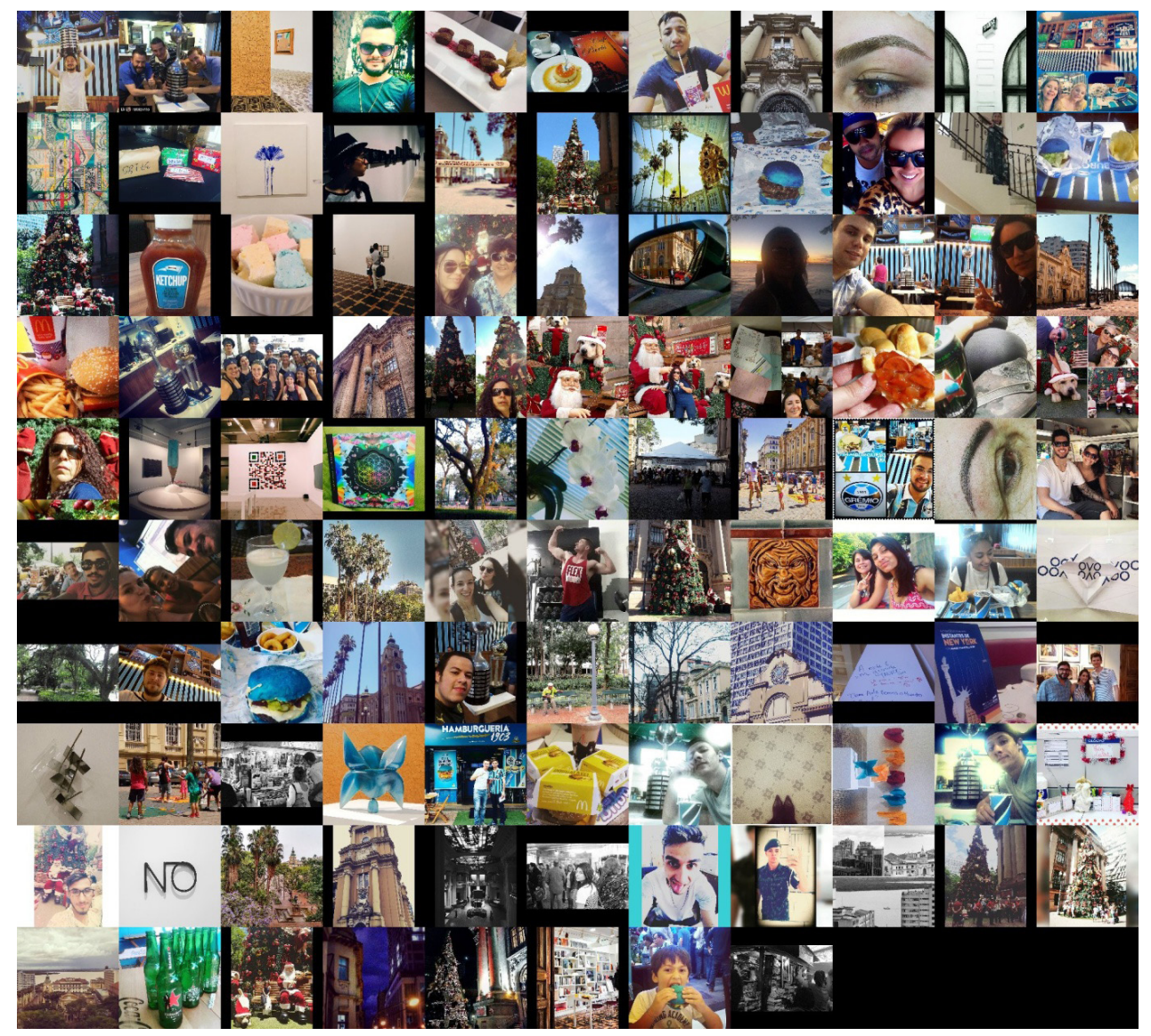

Figura 4 - Montagem das imagens após a Feira do Livro

Fonte: Os autores (2016)

Comparativamente, podemos perceber que a Figura 3 possui um maior número de pessoas nas imagens, enquanto a Figura 4 destaca mais objetos e paisagens. A ocorrência das categorias "pessoas" e "selfies" é quase 10\% maior na primeira montagem, sendo atribuídas a 143 publicações, ou seja, 52\% do total no período.

A Praça da Alfândega é um espaço público que possui outras atividades de lazer durante todo o ano, independentemente da Feira do Livro, pois três de seus prédios são espaços culturais que abrigam exposições e eventos, além de outros eventos ao ar livre. O que podemos compreender através dessa visão em conjunto é que durante a Feira do Livro o convívio social é mais valorizado. Os atos de passear na Feira, comprar livros, assistir a shows e palestras têm um caráter ritual. Enquanto que fora desse período, passa-se a retratar nas imagens o espaço em si e seu entorno: paisagem, arquitetura e gastronomia.

Rememorando a Praça da Alfândega desde uma perspectiva histórica - que a partir do final do século XIX passa a ocupar um espaço central na vida social e cultural da burguesia da cidade, sendo local de destaque na sociedade daquele período -, e fazendo um cruzamento com os dados obtidos nos dois períodos analisados, podemos propor que 
durante a Feira do Livro de Porto Alegre existe uma atualização dessa noção. O acontecimento anual da Feira funciona como uma espécie de resgate dessa função de centro aglutinador de ações sociais e culturais. A praça volta a adquirir um status destacado, deixando de ser, ao menos nesse período, um lugar apenas de passagem corriqueira.

Pensando também o local da praça caracterizado sempre pelos eventos que nela ocorrem e não por sua configuração física, como vimos anteriormente, percebemos que a Praça da Alfândega, ao tornar-se novamente um espaço centralizador do convívio e da cultura, acaba por resgatar seu aspecto intrínseco de sociabilidade, possibilitando, e dando importância, a emergência de laços sociais tão representados nas fotos analisadas no período da feira. O evento da Feira do Livro de Porto Alegre é, portanto, um evento transformador desse espaço, e o caracteriza e constitui, possibilitando sua ressignificação social. A praça transforma-se em centro cultural e de sociabilidade, um espaço que em si mesmo se apaga - como verificamos nas imagens comparadas -, para dar lugar às relações sociais.

Durante a Feira do Livro, foram observadas categorias com elementos indissociáveis do evento, como visto nas figuras 5 e 6 , com 60 publicações referentes a livros e 23 a autógrafos, respectivamente. Como já visto, nessas categorias é possível notar a presença de pessoas nas imagens, outra categoria atribuída a mais da metade das publicações no período.

Podemos relacionar a ocorrência frequente de compartilhamentos de imagens que apresentam capas de livros, livros autografados e sessões de autógrafo com a noção de Lipovetsky e Serroy (2015), apresentada anteriormente, de uma quarta era de estetização do mundo. As fotos coletadas neste trabalho mostram que de fato compartilhamos nas redes publicações relacionadas aos nossos gostos e a momentos que vivenciamos com fluidez, sem buscarmos nos aprofundar nessas questões. Nas imagens citadas, e que compõe parte considerável daquilo que foi compartilhado durante o período da feira, a importância está na singularidade e no momento, não na profundidade ou na permanência. Também fica evidente, tanto nas fotos da Feira do Livro de Porto Alegre quanto nas imagens da Bienal de Artes do Mercosul, o compartilhamento de pequenos momentos, de fragmentos, que constroem narrativas do cotidiano e que dizem respeito ao que os sujeitos fazem, como usufruem dos momentos e de que forma registram o que foi vivenciado, criando uma estetização do mundo em que habitam. 


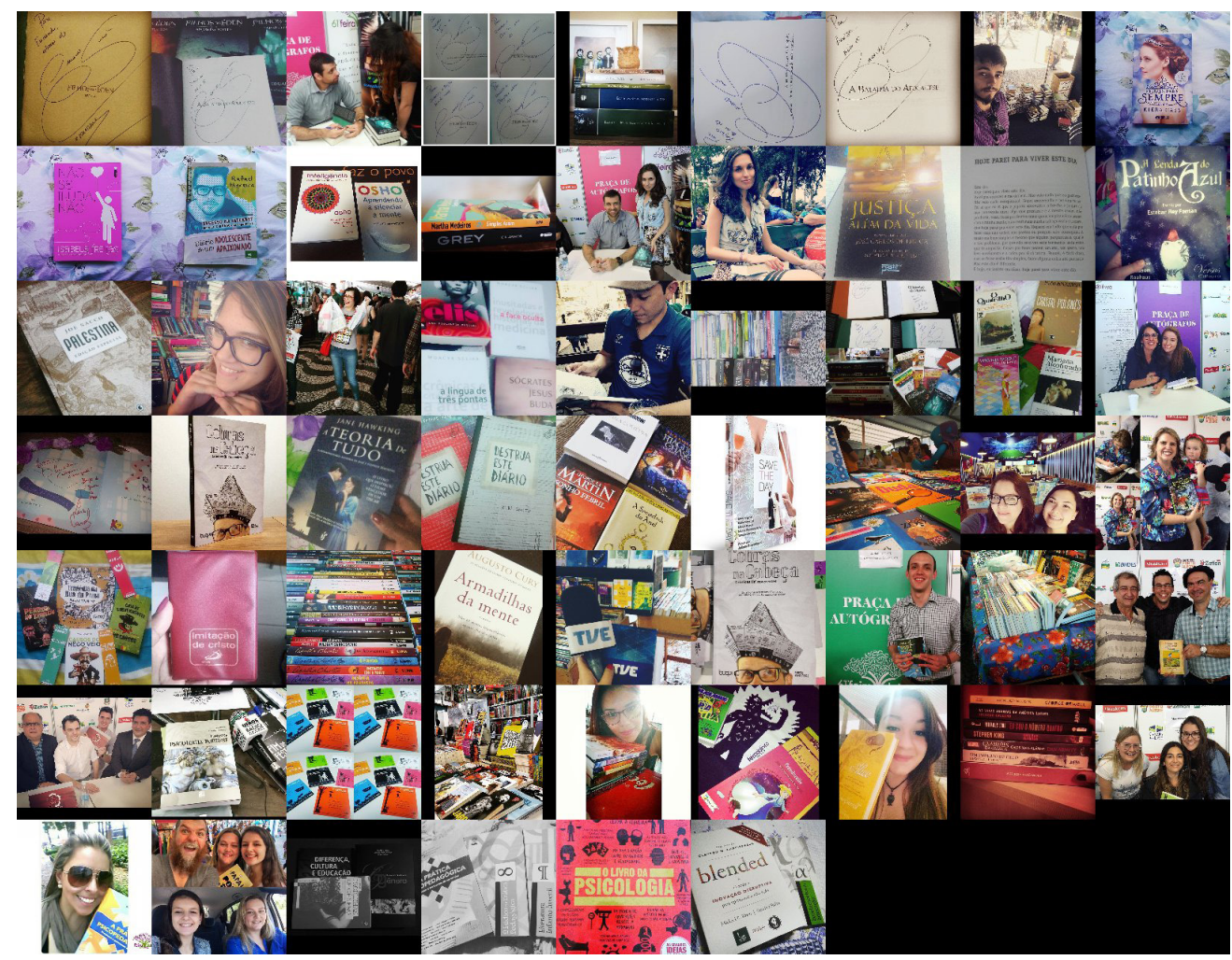

Figura 5 - Montagem das imagens da categoria "Livros"

Fonte: Os autores (2016)

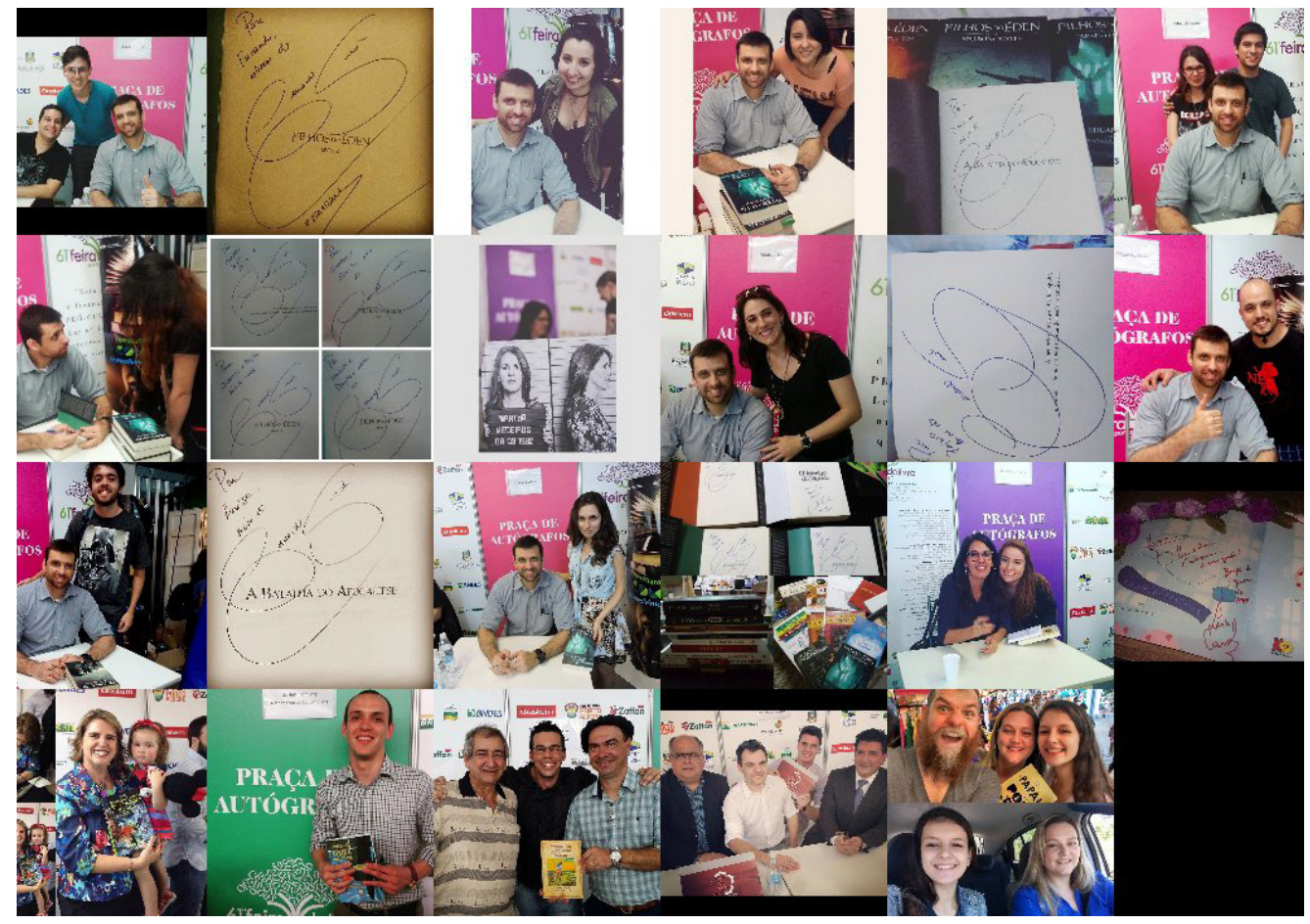

Figura 6 - Montagem das imagens da categoria "Autógrafos"

Fonte: Os autores (2016)

$54 \frac{\text { Comunicação \& Inovação, PPGCOM/USCS }}{\text { v. 17, n. 34 (40-58) maio-ago. } 2016}$ 
Em menor número, mas também referentes a práticas sociais nesse ambiente, há ocorrência de categorias ligadas a outras atividades na Feira, como a Bienal do Mercosul e a alimentação. Nesse último caso, as fotos são referentes à praça de alimentação montada no período da Feira, ao café do MARGS e à Hamburgueria 1903. Esse último estabelecimento, uma hamburgueria temática do time de futebol Grêmio, localizada em frente à Praça da Alfândega, na Rua dos Andradas, aparece em 26 publicações, e é responsável pela coloração azul que se destaca na montagem da Figura 2. Nesse segundo período, as categorias e o ambiente representado nas imagens estão mais relacionados ao cotidiano da praça. Entretanto, outro evento relacionado ao período fica evidente nas imagens, a decoração de Natal da praça, em frente ao prédio do Santander Cultural, e a campanha de arrecadação de brinquedos dos Correios, que são retratadas em 29 publicações.

Ao verificarmos o aumento da ocorrência de imagens que retratam a arquitetura e a paisagem da Praça e seus arredores e as experiências gastronômicas dos usuários no período posterior à Feira do Livro de Porto Alegre, é possível pensarmos esses dados a partir da perspectiva do nomadismo de Maffesoli (2004). Tanto a passagem pela Praça e pelo Centro Histórico da cidade são atividades do cotidiano, como o ato de se alimentar nas lanchonetes presentes no seu entorno. Entretanto, registrar e compartilhar esses momentos tanto efêmeros quanto triviais compõe um modo de vida ligado ao hedonismo, à necessidade de transformar os fragmentos do dia a dia em acontecimentos com um potencial de diversão e de aventura.

Em dois outros tipos de visualização, que utilizam as propriedades das imagens como parâmetro, em vez de categorias, é possível notar diferenças estéticas que auxiliam na compreensão das variedades culturais retratadas nos dois períodos. A Figura 7 traz um comparativo dos períodos (durante a Feira, no bloco superior, e depois dela, no bloco de fatias inferior da figura) por meio do fatiamento de um pixel de altura pela largura total das imagens. Sobrepostas, essas fatias mostram uma diferença de coloração que auxilia na construção de uma linguagem visual em torno da Praça da Alfândega em diferentes períodos do ano. Durante a Feira do Livro, há um espectro maior de cores, bem distribuído, sendo difícil identificar blocos de cores, por exemplo. Enquanto que na parte inferior da Figura 7, referente ao período pós-feira, é notável o predomínio de cores frias, como tons de azul e verde, bem como áreas em preto. É importante ressaltar que a cor preta nas extremidades laterais deve-se às bordas acrescentadas para uniformizar o tamanho das imagens, evitando cortes para análise do ImageJ. 


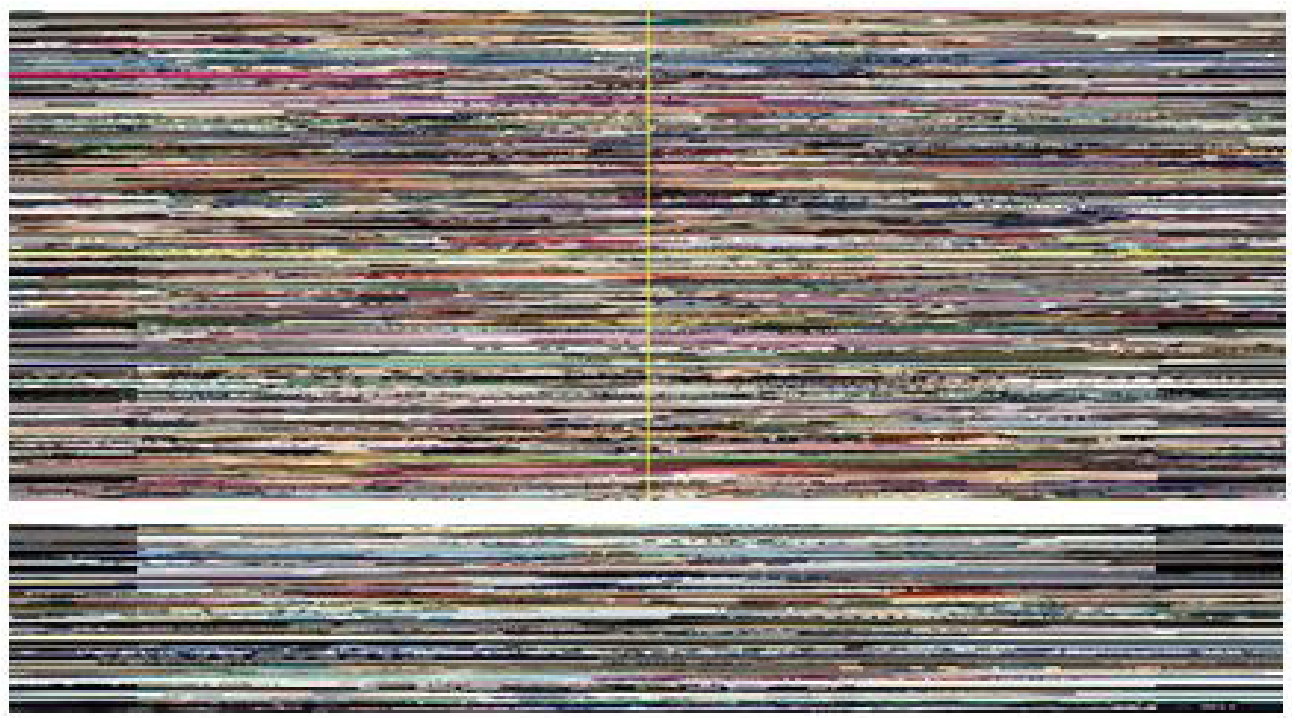

Figura 7 - Vista ortogonal horizontal das imagens

Fonte: Os autores (2016)

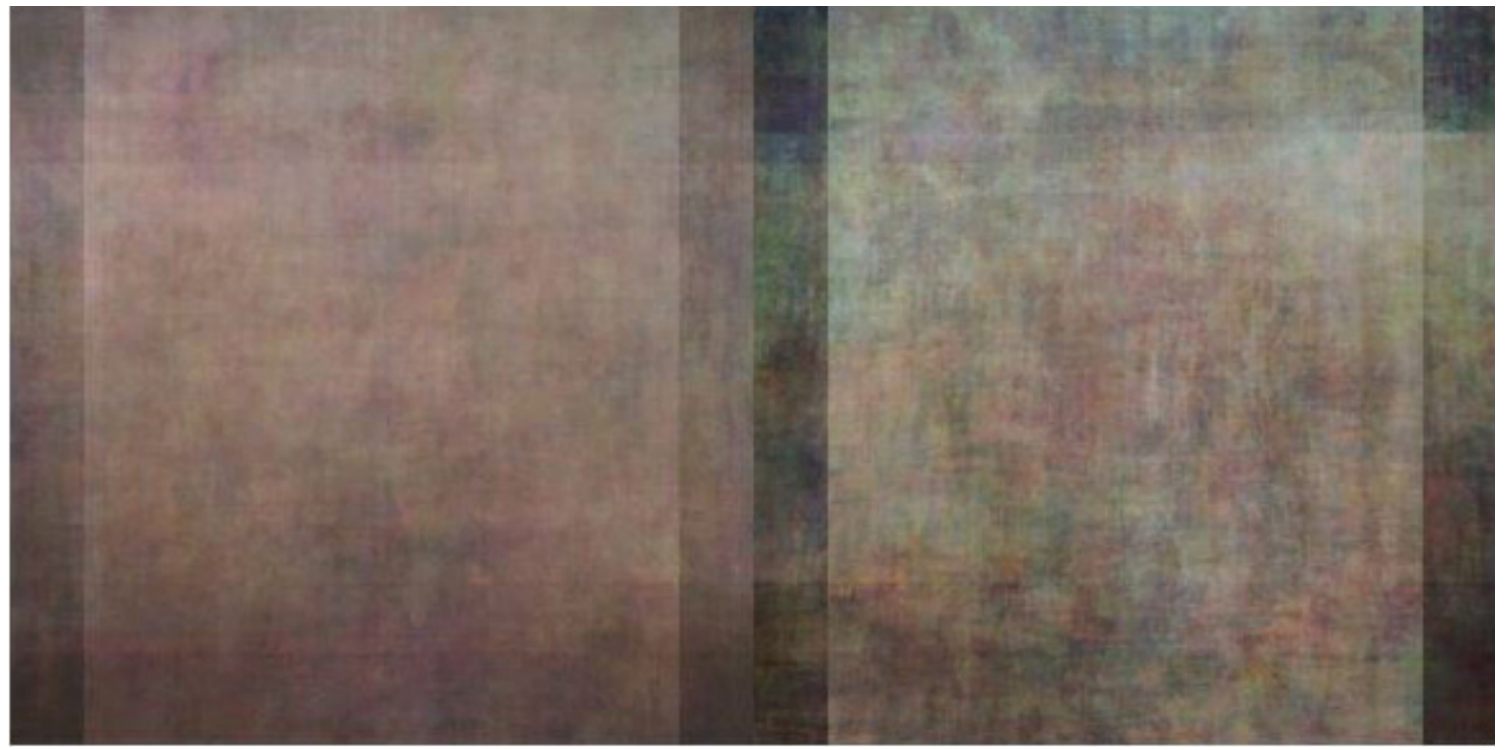

Figura 8 - Mediana de cores dos pixels das imagens durante e depois da Feira do Livro Fonte: Os autores (2016)

O mesmo pode ser notado na Figura 8, outro tipo de visualização chamado " $Z$ project”, também disponível no ImageJ. Nesse caso, é gerada uma imagem na qual cada pixel armazena a intensidade mediana de todas as imagens condensadas levando em consideração a localização do pixel correspondente. Assim, por serem mais coloridas, com níveis mais bem distribuídos, as imagens publicadas durante a Feira, correspondentes à mediana do lado esquerdo da Figura 8, têm tons quentes e homogêneos, se comparadas à mediana da direita, que apresenta maior variação de cores e predomínio de tons frios. 


\section{Considerações finais}

Retomando a noção de nomadismo (MAFFESOLI, 2004) aplicada a um local de referência simbólica da cidade de Porto Alegre, torna-se pertinente a observação de momentos anteriores e posteriores às atividades que alteram a percepção do local. Michel de Certeau (1984) comenta que o espaço é o resultado de uma complexa convivência social do lugar de interação. Portanto, o lugar se torna espaço ao ser apropriado por indivíduos dentro de um cotidiano específico.

Ao partir do pressuposto de que cada intervenção no sistema de rede social Instagram é resultado de uma motivação gerada por um evento que o indivíduo julgou ser pertinente estar conectado ao seu perfil público, podemos refletir sobre a compilação exposta neste texto. $\mathrm{O}$ fato de termos mais selfies nas imagens capturadas durante a Feira do Livro e mais imagens da arquitetura e paisagem da Praça sem a Feira nos mostra uma dicotomia instigante. Aparentemente a conexão com o espaço físico é maior nos momentos em que a Feira não está ocorrendo, porém, podemos também interpretar que o selfie é um elemento importante de pertencimento não só ao local físico, mas ao evento social. Registrar publicamente que se está dentro do evento é uma interação social relacionada ao pertencimento à comunidade. Nesse ato há a transformação do lugar em espaço, no qual a sociabilização transforma e reapropria os significados da geografia das interações. Assim, a Feira do Livro não poderia acontecer em outro lugar ou, se acontecesse, seria obrigatoriamente um outro evento social - da mesma forma, a Praça da Alfândega adquire sentido social diverso no período em que abriga a Feira do Livro.

Outra questão relevante desta pesquisa foi o cruzamento entre a técnica utilizada com o serviço IFTTT e a metodologia que Manovich (2010) vem desenvolvendo nos seus últimos trabalhos. Ao realizarmos essa combinação, nossa ideia foi testar um modo de compreender melhor as redes sociais, no caso o Instagram, e suas conexões relacionadas ao espaço físico. Entendemos que esse tópico cresce em pertinência à medida que as trocas sociais na internet começam a migrar paulatinamente para um ambiente móvel e ubíquo. Como constatamos neste texto, a partir das mudanças nas formas de acesso e na produção de conteúdo, as mensagens e os significados também devem ser alterados.

\section{Referências}

DE CERTEAU, M. The practice of everyday life. Berkeley: University of California Press, 1984. 
FLÔRES, A. R. O núcleo da Praça da Alfândega de Porto Alegre: Requalificação e convergência. 2005. Dissertação (Mestrado em Arquitetura e Urbanismo) - Universidade Federal do Rio Grande do Sul, Porto Alegre, 2005.

G1. Feira do Livro de Porto Alegre tem aumento nas vendas de 11,25\%. G1, Porto Alegre, 17 nov 2015. Disponível em:

$<$ http://g1.globo.com/rs/rio-grande-do-sul/noticia/2015/11/feira-do-livro-de-porto-alegre-registra-aumento-nas-vendas-de-1125.html>. Acesso em: 17 fev. 2016.

IGARZA, R. Burbujas de ocio: nuevas formas de consumo cultural. Buenos Aires: La Crujia, 2009.

INSTAGRAM. About Us. 2015 Disponível em: <http://instagram.com/about/us> Acesso em: 10 abr. 2015.

LEMOS, A. Cidade e mobilidade. Telefones celulares, funções pós-massivas e territórios informacionais. Revista Matrizes, São Paulo, v. 1, n. 1, p. 121-137, 2007. Disponível em: <http://www.matrizes. usp.br/index.php/matrizes/article/view/29>. Acesso em: 12 jul. 2015.

LIPOVETSKY, G; SERROY, J. A Estetização do Mundo: viver na era do capitalismo artista. São Paulo: Companhia das Letras, 2015.

LUCCHESE, A. $61^{\text {a }}$ Feira do Livro de Porto Alegre começa nesta sexta-feira. Zero Hora, Porto Alegre, 30 out. 2015. Disponível em: <http://zh.clicrbs.com.br/rs/entretenimento/noticia/2015/10/61-feira-do-livro-de-porto-alegre-comeca-nesta-sexta-feira-4889800.html>. Acesso em: 17 fev. 2016.

MAFFESOLI, M. El nomadismo: Vagabundeos iniciáticos. México: FCE, 2004.

MANOVICH, L. The Science of Culture? Social Computing, Digital Humanities, and Cultural Analytics. 2015. Disponível em <http://manovich.net/content/04-projects/086-cultural-analytics-social-computing/cultural_analytics_article_final.pdf>. Acesso em 5 dez. 2015.

What is visualization? [S.1.]: [s.n.], 2010. Disponível em: <http://manovich.net/content/04-projects/064-what-is-visualization/61_article_2010.pdf>. Acesso em: 5 dez. 2015.

MANOVICH, L.; DOUGLASS, J.; ZEPEL, T. How to compare one million images? [S.l.]: [s.n.], 2011. Disponível em: <http://manovich.net/content/04-projects/071-how-to-compare/68_article_2011_ sm.pdf $>$. Acesso em: 25 jul. 2015.

MITCHELL, W. e-topia: Tecnologias de informação e comunicação e a transformação da vida urbana. In: CASTELLS, M.; CARDOSO, G. A sociedade em rede: do conhecimento à acção política. Lisboa: Imprensa Nacional-Casa da Moeda, 2005. p. 335-343. 